\title{
Reproductive Versatility and the Epigenetic Control of Female Gametogenesis
}

\author{
J.-P. Vielle-Calzada, E. Hernández-Lagana, D. Rodríguez-Leal, \\ I. Rodríguez-Arévalo, G. León-Martínez, U. Abad-Vivero, E. Demesa-Árévalo, \\ A. Armenta-Medina, and C. Alvarez-Mejía \\ Group of Reproductive Development and Apomixis, Laboratorio Nacional de Genómica para la \\ Biodiversidad, CINVESTAV Irapuato, México \\ Correspondence: vielle@ira.cinvestav.mx
}

\begin{abstract}
Each year, plants and animals perform the task of repopulating the planet through patterns of courtship and mating that have a unifying and compelling logic: the production of offspring. Although life of nearly all organisms is organized around sex and breeding, Darwinian thinking focused more on the struggle for existence than on evolutionary significance of this frantic race to reproduce. In Darwin's own words, "We do not know the final cause of sexuality; why new beings should be produced by the union of the two sexual elements. The whole subject is hidden in darkness..." (Darwin 1862). In plants, a major consequence of this search for survival is the evolution of a multitude of reproductive alternatives that have intrigued botanists, geneticists, and evolutionary biologists for more than 100 years. Because sexually derived genetic diversity is interpreted as essential for adaptation, it is often thought that sex is necessary for the perpetuation of a species; however, many organismsincluding several hundred families of flowering plants - are going efficiently about propagating their kind without bothering with meiosis and mating. Whereas many plants can undergo vegetative propagation, through the production of stolons, bulbs, or rhizomes, for example, many others have developed methods to produce an embryo from a single cell whose nucleus is not formed by the fusion of two gametes, offering a direct developmental and evolutionary challenge to sexual reproduction. Recent evidence suggests that epigenetic mechanisms that control transcriptional silencing of DNA repetitive elements and heterochromatin are crucial for the acquisition of cell identity in the ovule, opening the possibility that the developmental distinction between sexual development and apomixis might have evolved as an adaptive response to evolutionary forces that modulate structural variation and reproductive versatility in flowering plants.
\end{abstract}

The emergence of all plants is derived from a common ancestor that endosymbiotically acquired a photosynthetic bacterium capable of transforming light into energy, an evolutionary event that changed the surface of the planet by progressively transforming an environment dominated by cyanobacteria (blue-green bacteria) into a habitat predominantly occupied by photosynthetic multicellular organisms. Although fossilized spores suggest that land plants appeared more than 450 million years ago, the establishment of their life cycle through the alternation of haploid and diploid generations remains an unsolved mystery. In contrast to green algae and mosses, in which the gametophytic (haploid) phase is free-living and temporally dominant, flowering plants have a reduced and ephemeral gametophyte that forms male and female gametes and is necessary to ensure sexual reproduction.

Plants have evolved a characteristic life strategy with alternating diploid and haploid phases (or generations), continuous postembryonic development that derives in the formation of aerial and underground meristems, and the absence of a germline established during early embryo differentiation. These specialized features have important implications for the development of gametes and seed formation. The life cycle of flowering plants consists of a dominant sporophytic generation and two morphologically different gametophytic phases taking place in specialized reproductive structures. The sporophyte is the diploid (2n) phase of a plant and is usually represented by the visible vegetative organs (roots, stems, leaves, and floral organs). The gametophyte is the haploid (1n) phase and is represented by a small number of reproductive cells that differentiate after meiosis within reproductive organs. Unlike in animals, where meiotic products differentiate directly into reproductive cells, the haploid cells of flowering plants undergo several division cycles before differentiating into gametes.

The establishment of the gametophytic phase presents an opportunity for establishing genetic filters that in the form of natural selection can act at the haploid level and eliminate the transmission of deleterious effects to the next generation, an evolutionary driving force that might be at the origin of mechanisms to ensure that reproductive development is tightly regulated (Walbot and Evans 2003; Calarco and Martienssen 2011). In addition to classic types of genetic control, the role of epigenetic regulation in plant development is emerging as a crucial element to understand genome instability, hybridization, and polyploidy. It is becoming clear that small RNA (sRNA)-dependent regulatory pathways can induce quantitative and qualitative regulatory changes that cause morphological variation, heterosis, and reproductive versatility, which are all mechanisms leading to an increase 
in the potential for adaptive evolution. The discovery of these epigenetic components is transforming our current view of the structural variation and diversity that prevails at key steps of female gametogenesis, with profound implications for understanding the evolutionary trends that shape reproductive development and adaptation to the environment.

\section{REPRODUCTIVE VERSATILITY IN FLOWERING PLANTS}

The large diversity of reproductive alternatives exhibited by flowering plants suggests that the mechanisms that lead to gamete formation and seed development might be flexible and to a large extent modular. For example, many species are able to generate viable seeds even without the fusion of sperm and egg by means of apomixis, a natural form of asexual reproduction through seeds that leads to viable offspring genetically identical to the mother plant. Although originally defined to include all known forms of vegetative propagation, the term has been restricted to name a series of inherited developmental mechanisms that give rise to clonal seeds by circumventing meiotically derived chromosome reduction and fertilization of the egg cell in the ovule.

Similarly to mammals, female gametogenesis in most flowering plants depends on the predetermined selection of a single meiotically derived cell, because the three other meiotic products die following meiosis II without any further division or differentiation. The genetic basis and molecular mechanisms that determine the selection and viability of a single gametic precursor are completely unknown. Whereas a single generative cell undergoes meiosis to produce four chromosomally reduced cells (the megaspores), in the majority of sexual species a single functional megaspore gives rise to the female gametophyte (Maheshwari 1950; Drews and Koltunow 2011). After significant cellular enlargement, the nucleus of the functional megaspore usually undergoes three rounds of mitosis before giving rise to a gametophyte composed of seven cells: two companion synergids, the egg cell, a binucleated central cell, and three antipodals. Double fertilization of both the egg and central cell is necessary to trigger embryogenesis and endosperm development, respectively. In contrast, plants that reproduce by apomixis can form embryos directly from a somatic cell in the developing unfertilized ovule (adventitious embryony) or from chromosomally unreduced female gametophytes in which the egg cell develops autonomously into an embryo by parthenogenesis (gametophytic apomixis). In the latter case, the female gametophyte can be formed from direct differentiation of somatic cells in the ovule (apospory) or from an aberrant cell division cycle that prevents reduction and recombination, sometimes completely bypassing meiosis (diplospory). In most cases, the formation of the endosperm is still dependent on fertilization of the central cell (pseudogamy), although rare cases of autonomous development of the endosperm have also been reported (Nogler 1984).
Cell specification during the formation of haploid gamete precursors is highly flexible in the ovule. In general, sexual species have been classified in three main types: monosporic, bisporic, or tetrasporic, depending on the number of meiotically derived nuclei that participate in the formation of the female gametophyte (for review, see Maheshwari 1950). Bisporic female gametophytes arise from one of the two cells formed after meiosis I, incorporating both nuclei resulting from meiosis II as gametic precursors that eventually give rise to distinct gametophytic cells after several rounds of division. In contrast, all four meiotically derived nuclei participate in the formation of the tetrasporic female gametophyte, generating a chimeric haploid multicellular entity that incorporates both maternally derived alleles into distinct gametophytic cells. Other alternative pathways of sexual development include many forms of multiple embryogenesis within the same ovule (polyembryony) (Koltunow et al. 1995), natural formation of unreduced gametes at variable frequencies (Harlan and de Wet 1975; Bretagnolle and Thompson 1995; Brownfield and Köhler 2011), and autonomous development of the egg cell by parthenogenesis (Kimber and Riley 1963).

Numerous mutants result in the formation of unreduced gametes in flowering plants ( $2 n$ gametes; Hermsen 1984; Veilleux 1985; Parrott and Smith 1986; D'Amato 1989; Bretagnolle and Thompson 1995). Many exhibit high sex specificity, suggesting genetic divergence between mechanisms controlling unreduced pollen and unreduced egg cell formation (Veronesi et al. 1986; Werner and Peloquin 1989; De Haan et al. 1992). Alleles responsible for $2 n$ gamete formation usually show a variable degree of penetrance and expressivity, and in the case of female gametogenesis, two types of meiotic aberrations are distinguished: first-division restitution (FDR) and seconddivision restitution (SDR). Whereas $2 n$ gametes derived from FDR occur after abnormal meiosis I and result in a single nucleus containing all nonsister chromatids, $2 n$ gametes derived from SDR result from chromosome replication after the normal completion of meiosis I. In both cases, two of the four chromatids of a homologous set of chromosomes are recovered in the offspring. Whereas in principle $2 n$ gametes derived from FDR preserve the parental genomic constitution, SDR usually results in highly homozygous $2 n$ gametes that have undergone normal meiotic recombination and do not transmit an intact parental contribution.

\section{EPIGENETIC CONTROL OF CELL SPECIFICATION IN THE ARABIDOPSIS OVULE}

Recent studies of the regulation of sexual reproduction in plants indicate that the genetic basis of female gametogenesis is complemented by epigenetic mechanisms that are crucial to control events that distinguish sexual from apomictic development (Grimanelli 2011; Rodriguez-Leal and Vielle-Calzada 2012). During the past 
few years, methods that allow the isolation of developing ovules or specific cells through laser-capture microdissection have opened up the possibility to conduct largescale transcriptional analysis of female reproductive development and harvesting of developing ovules of Arabidopsis thaliana (L.) Heynh (Arabidopsis) at specific developmental stages that encompass events that precede meiosis to fully differentiated organs (Schmidt et al. 2011; Sanchez-Leon et al. 2012; Schmid et al. 2012). Some of these efforts have resulted in the possibility of globally analyzing gene expression in whole developing ovule primordia, allowing the generation of full-length cDNA libraries, RNA-seq profiles, and large-scale analysis of DNA methylation states. Our strategies are currently focused on a molecular dissection of developmental stages that encompass female meiosis and the cellular relationships that prevail at the sporophytegametophyte intersection during functional megaspore differentiation. Using next-generation sequencing technologies, we were able to identify a multitude of transcripts that represent three types of regulation: (1) genes and noncoding RNAs (ncRNAs) that are specifically expressed in the female gametophyte, (2) genes and ncRNAs that are preferentially expressed in the female gametophyte as compared to sporophytic cells of the ovule, and (3) genes and ncRNAs that require the presence of a female gametophyte to be expressed in sporophytic cells of the ovule (Sanchez-Leon et al. 2012). Among them, specific genes encoding PIWI/PAZdomain ARGONAUTE proteins, as well as other regulators of the RNA-dependent DNA methylation (RdDM) pathway (Law and Jacobsen 2010), were highly expressed in either somatic cells surrounding the female gametophyte or specific gametophytic cells.

We recently showed that the Arabidopsis "slicer" protein ARGONAUTE9 (AGO9) controls female gametogenesis by restricting the specification of gamete precursors in a dosage-dependent, non-cell-autonomous manner. Mutations in $A G O 9$ lead to the differentiation of multiple female gamete precursors that are able to initiate gametogenesis and give rise to independent female gametophytes in the ovule, in a pattern reminiscent of aposporous apomixis (Olmedo-Monfil et al. 2010). The AGO9 protein is not expressed in the gamete lineage; instead, it is expressed in somatic companion cells. Strikingly, mutations in SUPPRESSOR OF GENE SILENCING3 and RNA-DEPENDENT RNA POLYMERASE6 exhibit an identical defect to ago 9 mutants, suggesting that the movement of sRNA silencing out of somatic companion cells is necessary for controlling the specification of gamete precursors; however, these two pathways have been defined as independent and unrelated. Although in the ovule AGO9 preferentially interacts with 24-nucleotide sRNAs derived from transposable elements (TEs), and its activity is necessary to silence TEs in female gametes and their accessory cells, it is not yet clear if RNA-dependent silencing of repetitive elements is directly related to the ago 9 phenotype or if this phenotype is dependent on other sRNAs that also interact with AGO9, such as microRNAs or other 21-nucleotide small interfering RNAs (siRNAs). Predominant TE targets of AGO9 are located in the pericentromeric regions of all five chromosomes, suggesting a link between the AGO9dependent sRNA pathway and heterochromatin formation. $A G O 104$, the likely homolog of $A G O 9$ in maize, also gives rise to unreduced gametes, although through a different developmental and morphological configuration that does not depend on ectopic cell differentiation (Singh et al. 2011). Additionally, the inactivation of a distinct methylation pathway in female reproductive organs results in defective cell specification within the ovule (Garcia-Aguilar et al. 2010), suggesting a role in the distinction between sexual and apomictic reproduction. Our results suggest a causative link between epigenetic regulation and the natural reproductive versatility found in flowering plants.

\section{NEW MODELS FOR INVESTIGATING THE EPIGENETIC CONTROL OF GAMETOGENESIS}

The developmental convergence that links sexual development to apomixis would benefit from the establishment of new approaches to better integrate a wide diversity of studies on the biology of plant reproduction with new knowledge on the genetic and epigenetic basis of female gametogenesis. The elucidation of the mechanisms that regulate ovule and female gametophyte development in new species will bring important insights into the mechanisms that distinguish sexuality from apomixis (Table 1). For example, tetrasporic female gametogenesis occurs in Adoxa moschatellina L. (Five-faced Bishop), a species growing in hedgerows of Colorado and New

Table 1. Alternative plant species to study the epigenetic regulation of female gametogenesis

\begin{tabular}{llccl}
\hline Species & Division & $\begin{array}{c}\text { Chromosomal } \\
\text { constitution }\end{array}$ & $\begin{array}{c}\text { 1C DNA } \\
\text { (genome size) }\end{array}$ & $\begin{array}{c}\text { Method of } \\
\text { reproduction }\end{array}$ \\
\hline $\begin{array}{llcl}\text { Marchantia polymorpha } \\
\text { Adoxa moschatellina L. }\end{array}$ & $\begin{array}{l}\text { Marchantiophyta } \\
\text { Magnoliophyta }\end{array}$ & $\begin{array}{c}n=9 \\
2 n=36\end{array}$ & $0.32 \mathrm{pg}(290 \mathrm{Mb})^{\mathrm{a}}$ & $\begin{array}{c}\text { Sexual } \\
\text { Sexual tetrasporic }\end{array}$
\end{tabular}

Ranunculus auricomus agamic complex

Ranunculus cassubicus subgroup

$R$. cassubicifolius W. Koch

Magnoliophyta

$2 n=16$

$3.11 \mathrm{pg}(3.04 \mathrm{~Gb})^{\mathrm{c}}$

$R$ carpaticola Soó

Magnoliophyta

$2 n=16$

$3.06 \mathrm{pg}(2.99 \mathrm{~Gb})^{\mathrm{c}}$

Sexual monosporic Sexual monosporic

\footnotetext{
${ }^{\mathrm{a}} \mathrm{Nasu}$ et al. 1997.

${ }^{\mathrm{b}}$ Greilhuber 1979.

${ }^{\mathrm{c}}$ Hörandl and Greilhuber 2002.
} 

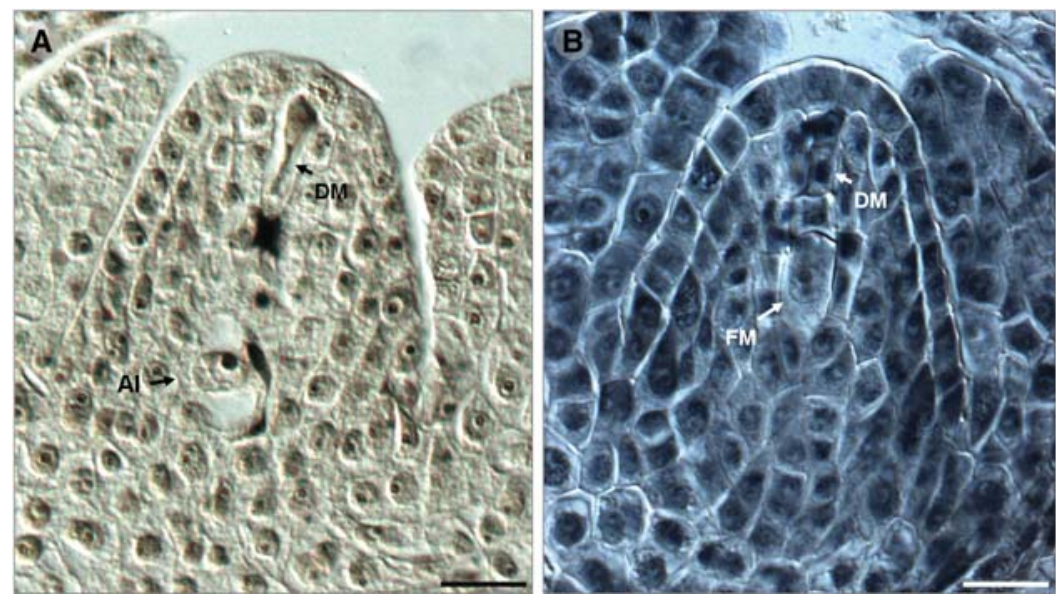

Figure 1. Initiation of apomictic and sexual development in the developing ovule of Ranunculus auricomus. (A) Initiation of apomixis (apospory); in the vicinity of the remnants of degenerated meiotic products (DM), a somatic (sporophytic) cell differentiates into a gametic precursor $(\mathrm{AI})$ in the absence of meiosis. $(B)$ Initiation of sexual gametogenesis; four haploid cells are generated following meiosis, three of which degenerate (DM) and one differentiates in the functional megaspore (FM). (Micrographs obtained from examination of cytological sections generated by A. Rutishauser and G. Nogler.) Bar, $20 \mu \mathrm{m}$.

Mexico (but also in the British Isles and many temperate regions of Europe) that represents the sole member of the genus Adoxa. The reproductive life cycle and floral architecture of A. moschatellina offers many opportunities to establish genetic strategies to investigate cell-to-cell interactions at the gametophytic level and preferential inheritance between the egg apparatus and one polar nucleus (that inherits one maternal allelic variant) and the antipodals and the second polar nucleus (inheriting the second maternal allelic variant). The possibility of mutagenizing this species with insertional elements that act as enhancer detectors or gene traps to monitor endogenous gene expression could allow rapid association of abnormal phenotypes with patterns of transcriptional activity in heterozygous individuals inheriting a single copy of the insertional element. Although natural populations have a strong tendency to behave as false diploids $(2 n=4 x=36)$, underrepresented ecotypes have a tendency to contain individuals that are smaller and fast growing as compared to reference plants, suggesting the possibility that true diploids might be present in extant natural populations. In addition, establishing genetic systems to study the prevalent gametophytic phase of nonvascular bryophytes such as Marchantia polymorpha could allow a better understanding of the evolutionary mechanisms that have shaped the reproductive function of widely studied epigenetic pathways (Table 1). The fast life cycle, small genome, and facility of growth under nutritionally poor substrates allow the possibility of rapidly testing for developmental convergences controlling gametogenesis in bryophytes and flowering plants, including possible responses to environmental cues that directly affect epigenetic regulation of previously described pathways. Finally, direct comparison of the role of epigenetic regulation on the function of genes that act during both sexual and apomictic development within the same species could become possible by establishing molecular genetic approaches in the Ranunculus auricomus complex (Fig. 1), a group of sexual (diploid; $2 n=16$ ) self-incompatible species that includes $R$. cassubiciolius and $R$. carpaticola as well as their interspecific apomictic and polyploid hybrid derivatives (Hörandl and Temsch 2009). Results of classic cytogenetic investigations of apomixis in $R$. auricomus demonstrated that in this species, apospory is inherited monogenetically (Rutishauser 1965; Nogler 1971) and segregation analysis suggested that the allelic variant of the genetic locus conferring the initiation of aposporous gametic precursors is dominant over a "wild-type" allelic variant that is involved in the control of female meiosis in sexual individuals (Nogler 1984). These and other systems offer the opportunity to investigate many developmental problems related to the reproductive versatility that prevails in extant flowering plants, contributing to establishing the basis of a highorder understanding of the mechanisms that shape plant reproductive variation, evolution, and diversity. In addition, the elucidation of the control of apomixis could potentially transform our current view of agricultural biotechnology, but also animal cloning or limb regeneration (Vogel 2005). We anticipate that imminent discoveries in the field of plant epigenetics are going to quickly transform our basic understanding of the fundamental mechanisms that distinguish sexuality from apomixis in a plant ovule.

\section{ACKNOWLEDGMENTS}

We thank Gian Nogler for a gift of cytological slides depicting sexual and apomictic development in R. auricomus and Rich Jorgensen for critical comments. Our research is being funded by Consejo Nacional de Ciencia y Tecnología (CONACyT), the Howard Hughes Medical Institute International program, and as part of DuPont Pioneer regional initiatives to benefit local subsistence farmers. 


\section{REFERENCES}

Bretagnolle F, Thompson JD. 1995. Gametes with the somatic chromosome number: Mechanisms of their formation and role in the evolution of autopolyploid plants. New Phytol 129: $1-22$.

Brownfield L, Köhler C. 2011. Unreduced gamete formation in plants: Mechanisms and prospects. J Exp Bot 62: 1659-1668.

Calarco JP, Martienssen RA. 2011. Genome reprogramming and small interfering RNA in the Arabidopsis germline. Curr Opin Genet Dev 21: 134-139.

D'Amato F. 1989. Polyploidy in cell differentiation. Caryologis 42: $183-211$

Darwin CR. 1862. On the two forms, or dimorphic-condition, in the species of Primula and on their remarkable sexual relations. J Proc Linnean Soc Botany. London.

De Haan A, Marceira NO, Lumaret R, Delay J. 1992. Production of $2 n$ gametes in diploid subspecies of Dactylis glomerata L. 2. Occurrence and frequency of $2 n$ eggs. Ann Bot 69: $345-350$.

Drews GN, Koltunow AM. 2011. The female gametophyte. Arabidopsis Book 9: e0155.

Garcia-Aguilar M, Michaud C, Leblanc O, Grimanelli D. 2010. Inactivation of a DNA methylation pathway in maize reproductive organs results in apomixis-like phenotypes. Plant Cell 22: $3249-3267$

Greilhuber J. 1979. C-band distribution, DNA content and base composition in Adoxa moschatellina (Adoxaceae), a plant with cold-sensitive chromosome segments. Plant System Evol 31: 243-259.

Grimanelli D. 2011. Epigenetic regulation of reproductive development and the emergence of apomixis. Curr Opin Plant Biol 15: 57-62.

Harlan JR, de Wet JM. 1975. On Ö Winge and a prayer: The origins of polyploidy. Bot Rev 41: 361-390.

Hermsen JGT. 1984. Mechanisms and genetic implications of $2 n$ gamete formation. Iowa State J Res 58: 421-434.

Hörandl E, Greilhuber J. 2002. Diploid and autotetraploid sexuals and their relationships to apomicts in the Ranunculus cassubicus group: Insights from DNA content and isozyme variation. Plant System Evol 234: 85-100.

Hörandl E, Temsch EM. 2009. Introgression of apomixis into sexual species is inhibited by mentor effects and ploidy barriers in the Ranunculus auricomus complex. Ann Bot 104: $81-89$.

Kimber G, Riley H. 1963. Haploid angiosperms. Bot Rev 29: 480-531.

Koltunow AM, Bicknell RA, Chaudhury AM. 1995. Apomixis: Molecular strategies for the generation of genetically identical seeds without fertilization. Plant Physiol 108: 1345-1352.

Law JA, Jacobsen SE. 2010. Establishing, maintaining and modifying DNA methylation patterns in plants and animals. Nat Rev Genet 11: 204-220.

Maheshwari P. 1950. An introduction to the embryology of angiosperm. McGraw-Hill, New York.

Nasu M, Tani K, Hattori C, Honda M, Shimaoka T, Yamaguchi N, Katoh K. 1997. Efficient transformation of Marchantia polymorpha that is haploid and has very small genome DNA. J Ferment Bioeng 84: 519-552.

Nogler GA. 1975. Genetics of apospory in Ranunculus auricomus. IV. Embryology of F3 and F4 backcross offspring. Phytomorphol 25: 485-490.

Nogler GA. 1971. Genetik der Aposporie bei Ranunculus auricomus s.1. W. Koch. I. Embryologie. Ber Schweiz Bot Ges 81: 139-179.

Nogler GA. 1984. Gametophytic apomixis. In Embryology of Angiosperms (ed. John BM), pp. 475-518. Springer-Verlag, Berlin.

Olmedo-Monfil V, Duran-Figueroa N, Arteaga-Vazquez M, Demesa-Arevalo E, Autran D, Grimanelli D, Slotkin RK, Martienssen RA, Vielle-Calzada JP. 2010. Control of female gamete formation by a small RNA pathway in Arabidopsis. Nature 464: 628-632.

Parrott WA, Smith RR. 1986. Production of $2 n$ pollen in red clover. Crop Sci 24: 469-472.

Rodriguez-Leal D, Vielle-Calzada JP. 2012. Regulation of apomixis: Learning from sexual experience. Curr Opin Plant Biol 15: $549-555$.

Rutishauser A. 1965. Genetik der Pseudogamie bei Ranunculus auricomus s.1. W. Koch. Ber Schweiz Bot Ges 75: 157-182.

Sanchez-Leon N, Arteaga-Vazquez M, Alvarez-Mejia C, Mendiola-Soto J, Duran-Figueroa N, Rodriguez-Leal D, Rodriguez-Arevalo I, Garcia-Campayo V, Garcia-Aguilar M, Olmedo-Monfil V, et al. 2012. Transcriptional analysis of the Arabidopsis ovule by massively parallel signature sequencing. J Exp Bot 63: 3829-3842.

Schmid MW, Schmidt A, Klostermeier UC, Barann M, Rosenstiel P, Grossniklaus U. 2012. A powerful method for transcriptional profiling of specific cell types in eukaryotes: Laser-assisted microdissection and RNA sequencing. PLoS Biol 9: e1001155.

Schmidt A, Wuest SE, Vijverberg K, Baroux C, Kleen D, Grossniklaus U. 2011. Trancriptome analysis of the Arabidopsis megaspore mother cell uncovers the importance of RNA helicases for plant germline development. PLoS Biol 9: e1001155.

Singh M, Goel S, Meeley RB, Dantec C, Parrinello H, Michaud C, Leblanc O, Grimanelli D. 2011. Production of viable gametes without meiosis in maize deficient for an ARGONAUTE protein. Plant Cell 23: 443-458.

Veilleux R. 1985. Diploid and polyploid gametes in crop plants: Mechanisms of formation and utilization in plant breeding. Plant Breed Rev 3: 253-288.

Veronesi F, Mariana A, Bingham ET. 1986. Unreduced gametes in diploid Medicago and their importance in alfalfa breeding. Theor Appl Genet 72: 37-41.

Vogel G. 2005. How does a single somatic cell become a whole plant? Science 309: 86.

Walbot V, Evans MM. 2003. Unique features of the plant life cycle and their consequences. Nat Rev Genet 4: 369-379.

Werner JE, Peloquin SJ. 1989. Occurrence of $2 n$ pollen and PS gene frequencies in cultivated groups and their related wild species in tuber-bearing Solanums. Theor Appl Genet 78: 329-336. 


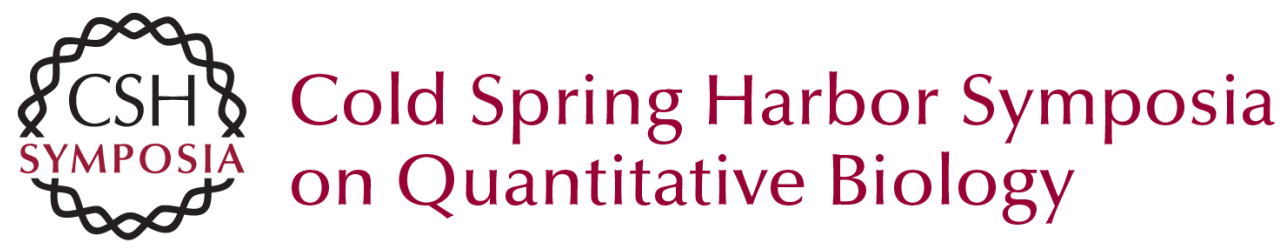

\section{Reproductive Versatility and the Epigenetic Control of Female Gametogenesis}

J.-P. Vielle-Calzada, E. Hernández-Lagana, D. Rodríguez-Leal, et al.

Cold Spring Harb Symp Quant Biol 2012 77: 17-21 originally published online December 18, 2012

Access the most recent version at doi:10.1101/sqb.2012.77.014894

References This article cites 32 articles, 3 of which can be accessed free at: http://symposium.cshlp.org/content/77/17.full.html\#ref-list-1

\section{License}

Email Alerting Receive free email alerts when new articles cite this article - sign up in Service the box at the top right corner of the article or click here. 